\title{
Health beliefs and use of dietary supplements among teachers \\ Öğretmenlerin sağlık inanışları ve diyet suplemanı kullanma durumu
}

\author{
Hülya Yardımc1 ${ }^{1}$ \\ Büşra Başpınar ${ }^{2}$ \\ Ayşe Özfer Özçelik ${ }^{3}$
}

Özet

$\mathrm{Bu}$ çalışma öğretmenlerin beslenme desteği kullanma durumları, sağlık inanışları ile vitaminler ve mineraller hakkinda bilgilerini belirlemek amacıyla planlanmıştır. Çalışma, Ankara'da çalışan 282 öğretmen üzerinde yürütülmüştür. Anket formu yardımıyla genel bilgileri, vitamin-mineral kullanımları, diyet suplemanları ile ilgili bilgi soruları ve sağlık inanışları değerlendirilmiştir. Elde edilen veriler SPSS paket programıla değerlendirilmiştir. Çalışmaya katılan öğretmenlerin 218'i kadın (\%77.3), 64'ü erkek olup (\%22.7) ortalama yaş $37.1 \pm 7.6$ yıldır. Öğretmenlerin \%41.5' 1 (117 kişi) ek vitamin-mineral kullandığını belirtmiştir. Katılımcıların vitamin-minerallerle ilgili ortalama bilgi puanının 14.3 \pm 2.6 olduğu, kadınların ortalama bilgi puanlarının erkeklerin ortalama bilgi puanlarına göre anlamlı olarak daha yüksek olduğu belirlenmiştir $(\mathrm{p}<0.05)$. Öğretmenlerin ortalama sağlık inanış puanı $29.2 \pm 2.8$ olup, cinsiyete ve yaş gruplarına göre alınan ortalama inanış puanının istatistiksel olarak anlamlı olduğu belirlenmiştir $(\mathrm{p}<0.05)$. Öğretmenlerin supleman kullanımının sağlik inanış1 $(p<0.01)$, kronik hastalık $(p<0.01)$, beslenme ile ilgili haberleri takip etme $(p<0.05)$ ile ilişkili olduğu belirlenmiştir. Diyet suplemanlarının sağlık personelinin gerekli

1Dr., Ankara University, Faculty of Health Sciences, Nutrition and Dietetic Department, hulyardimci@gmail.com

${ }^{2}$ Res. Assist. (MD), Ankara University, Faculty of Health Sciences, Nutrition and Dietetic Department, busrabaspinar92@gmail.com

${ }_{3}^{3}$ Prof. Dr., Ankara University, Faculty of Health Sciences, Nutrition and Dietetic Department, ozferozcelik@gmail.com Submitted: 2018-01-16 Published: 2018-03-06 
Yardımcı, H., Başpınar, B., \& Özfer Özçelik, A. (2018). Öğretmenlerin sağlık inanışlanı ve diyet suplemanı kullanma durumu. Journal of Human Sciences, 15(1), 331-339. doi:10.14687/jhs.v15i1.5191

appropriate to use dietary supplements if the gördügü zaman önermesi durumunda healthcare staff recommends it when it is kullanilmasi daha uygun olacaktır. needed.

Keywords: Teacher; vitamin; mineral; dietary Anahtar Kelimeler: Öğretmen; vitamin; supplements; health belief.

(Extended English summary is at the end of this document) mineral; besin destekleri; sağlık inanışı.

\section{GİRİ̧̧}

Beslenme, sağlıklı yaşamın sürdürülmesinde ve hastalıklardan korunmada anahtar rol oynamaktadır (Alhomoud ve ark., 2016). Yeterli ve dengeli beslenme ile vücudun gereksinimi olan esansiyel besin ve besin ögelerinin sağlanması amaçlanmaktadır. Dünyada ilk on ölüm nedeni arasında olan enfeksiyon hastalıklarının artışında genel risk faktörü olan mikrobesin ögesi yetersizlikleri önemli bir halk sağllğı problemidir (WHO, 2007). Günümüzde yaklaşık 2 milyon kişide vitamin-mineral yetersizliği olduğu tahmin edilmektedir (Micronutrient, 2009). Bu bağlamda diyet suplemanlarının tamamlayıcı ve tedavi edici etkisi göz ardı edilmemelidir. Diyet suplemanlarının sağlık ve hastalıktaki rolü kapsamlı bir şekilde incelendiğinde hücre savunması, antioksidan mekanizmalar ve kronik hastalıkların önlenmesinde etkili olduğu görülmektedir (Block ve ark., 2007; Al-Naggar \& Chen, 2011). Bu durum diyet suplemanlarının kullanılmas1 ve farkındalığın artmasına yol açmışır (Sharma ve Adiga, 2014). Bununla birlikte dünya genelinde kullanım sıklığ giderek artan diyet suplemanları (Waddington ve ark., 2015) ile ilgili yeterli düzenlemelerin ve gözetimin olmayışı, genel sağlığın olumsuz etkilenmesine yol açabilir (Fontanarosa ve ark., 2003). Diyet suplemanlarının kullanılması ile oluşabilecek nörolojik bozukluklar, gastrointestinal semptomlar, hepatotoksisite, doğum kusurları ve ilaç etkileşimleri gibi potansiyel yan etkiler sıklıkla endişe yaratmaktadır (Al-Naggar \& Chen, 2011).

Vitamin-mineral suplemanlarının akılcı kullanımında ve uygun seçimlerin yapılmasında beslenme bilgisi belirleyici olmaktadır (Sharma \& Adiga, 2014). Yaşam boyu devam eden süreçte beslenme alışkanlıklarının şekillenmesinde ailenin yanı sıra öğretmenlerin de olumlu davranışlar oluşturmada rolü büyüktür (Hall ve ark., 2016). Öğretmenler, otorite figürü ve rol model olarak birçok yolla öğrencilerin beslenme davranışlarını etkilemektedir (Perikkou ve ark., 2015). Son yıllarda yapılan bir çalısmada öğretmenlerin beslenme bilgilerinin öğrencilerinin sağlıklı tercihler yapmasında etkili olduğu belirlenmiştir (Hall ve ark., 2016). Bu nedenle öğretmenlerin doğru beslenme alısskanlıkları ve yeterli düzeyde bilgi sahibi olmaları, diyet suplemanı kullanımı gibi henüz fikir birliğine varılamayan konularda doğru adımların atılmasında etkili olacaktır.

Literatürde supleman kullanımının, supleman hakkında bilgi ve beslenme davranışlarını önemli ölçüde etkileyen sağlık inanışları arasındaki ilişkiyi inceleyen az sayıda çalışmaya rastlanmıstır. Bu çalışma öğretmenlerin beslenme desteği kullanma durumları, sağlık inanışları ile vitaminler ve mineraller hakkında bilgilerini belirlemek amacıyla planlanmıştır. 
Yardımcı, H., Başpınar, B., \& Özfer Özçelik, A. (2018). Öğretmenlerin sağlık inanışlanı ve diyet suplemanı kullanma durumu. Journal of Human Sciences, 15(1), 331-339. doi:10.14687/jhs.v15i1.5191

\section{YÖNTEM}

\subsection{Araştırma Zamanı ve Örneklem}

Araştırma Mart 2016-Mayıs 2016 tarihleri arasında yapılan kesitsel bir çalışmadır. Çalışmanın örneklemini Ankara'da olan çeşitli ilköğretim okullarında çalışan yaşları 21 ile 58 arasında olan gönüllü 282 öğretmen oluşturmuştur. Araştırmada Helsinki Deklerasyonu prensiplerine uyulmuştur.

\subsection{Veri Toplama Araçları}

Araştırma verileri, gönüllü onam formunu imzalayan öğretmenlerle, anket formu kullanılarak ve yüz yüze görüşülerek toplanmıştır. Anket formu, konu ile ilgili daha önce yapılan bazı çalışmalar incelenerek, oluşturulmasında bu kaynaklardan yararlanılmıştır (Eldridge \& Sheehan, 1992; Yeh, 2000; Conner ve ark., 2011; Sharma \& Adiga, 2014). Anket formunda öğretmenler hakkında genel bilgiler, vitamin-mineral desteği kullanımı, bilgi soruları ve sağlık inanışları olmak üzere dört bölüm yer almıştır. Bilgi sorularında, öğretmenlerin vitamin-mineraller ve diyet suplemanlarıyla ilgili bilgileri sorgulanmıştır.

Vitamin-minerallerle ilgili bilgi soruları literatürde yer alan çalşmalardan derlenmiştir (Eldridge \& Sheehan, 1992; Yeh, 2000; Conner ve ark., 2011). Bu bilgi sorularında (toplam 20 soru) her doğru cevap için "1 puan", yanlış cevap için "0 puan" verilerek (en az 0 puan, en çok 20 puan) toplam bilgi puanı hesaplanmıştır. Sağlık inanış soruları için (toplam 9 soru) yine literatürden yararlanılmış, 5'li likert tipi ölçek ("Kesinlikle Katılmıyorum", "Katılmıyorum", "Kararsızım" "Katıllyorum", "Kesinlikle Katıllyorum") kullanılarak inanış puanları (en az 0 puan, en çok 45 puan) hesaplanmıştır.

\subsection{Verilerin Analizi}

Araştırma verileri SPSS paket programı yardımı ile değerlendirerek, istatistiksel analizler yapılmıştır. Verilerin değerlendirilmesinde tanımlayıcı istatistikler, Ki-kare $\left(X^{2}\right)$ testi, bağımsız gruplarda t-testi kullanılmıstır. Sonuçlar $p=0.05$ anlamlılık düzeyinde değerlendirilmiştir. Değ işken olarak cinsiyet, yaş, kronik hastalık varlığı alınmıştır.

\section{BULGULAR}

Çalışmanın örneklemini oluşturan öğretmenlerin \%77.3'ü ( $n=218)$ kadın, \%22.7'si ( $n=64)$

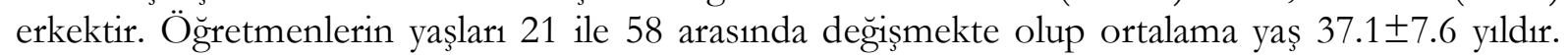
Öğretmenlerin \%83.3'ü evlidir. Öğretmenlerin \%21.6's1 öğrenim hayatlar1 süresince beslenme ile ilgili en az bir kez teorik ders aldıklarını belirtmiştir. Öğretmenlerin \%89.0'u beslenme ile ilgili haberleri takip etmektedir (Tablo 1). Beslenme haberlerini takip eden kadın öğretmenlerin oranı $(\% 91,7)$, erkek öğretmenlerinkinden $(\% 79,7)$ daha yüksek olup istatistiksel olarak anlamlıdır $(p<0.05)$. Beslenme ile ilgili haberler sirasiyla en fazla televizyon ve/veya radyodan $(\% 77.6)$, gazete ve/veya dergiden (\%62.5), internetten (\%49.4) ve kitaplardan (\%25.9) edinilmiştir.

Öğretmenlerin \%28.0’i kronik hastalığı olduğunu belirtmiştir (Tablo 1). Kadınlarda kronik hastalık görülme sılklğının (\%32.6) erkeklerden (\%12.5) daha yüksek olduğu belirlenmiştir $(p<0.05)$. Kadınlarda en sık görülen kronik hastalıklar sırasıyla demir yetersizliği (\%32.6), iyot yetersizliği hastalıkları (\%11.9), osteoporoz ve hipertansiyon (\%4.1) iken; erkeklerde ise en s1k görülen hastalıklar sirasıyla hipertansiyon (\%50), diyabet (\%25), osteoporozdur $(\% 12.5)$. Öğretmenlerin \%2.5'i özel bir diyet uyguladığını beyan etmiştir. Kronik hastalığ1 olan öğretmenlerin \%6.3'ünün diyet uyguladığ1 ve bu durumun istatistiksel olarak anlamlı olduğu belirlenmiştir $(\mathrm{p}<0.05)$. 

durumu. Journal of Human Sciences, 15(1), 331-339. doi:10.14687/jhs.v15i1.5191

Kronik hastalığ1 olan öğretmenlerin, olmayanlara göre; beslenme ile ilgili haberleri takip edenlerin takip etmeyenlere göre, supleman kullanma sıklı̆ının anlamlı olarak daha yüksek olduğu belirlenmiştir $(\mathrm{p}<0.05)$.

Tablo 1. Öğretmenlerin bazı özelliklerinin diyet suplemanı kullanımı üzerindeki etkisi

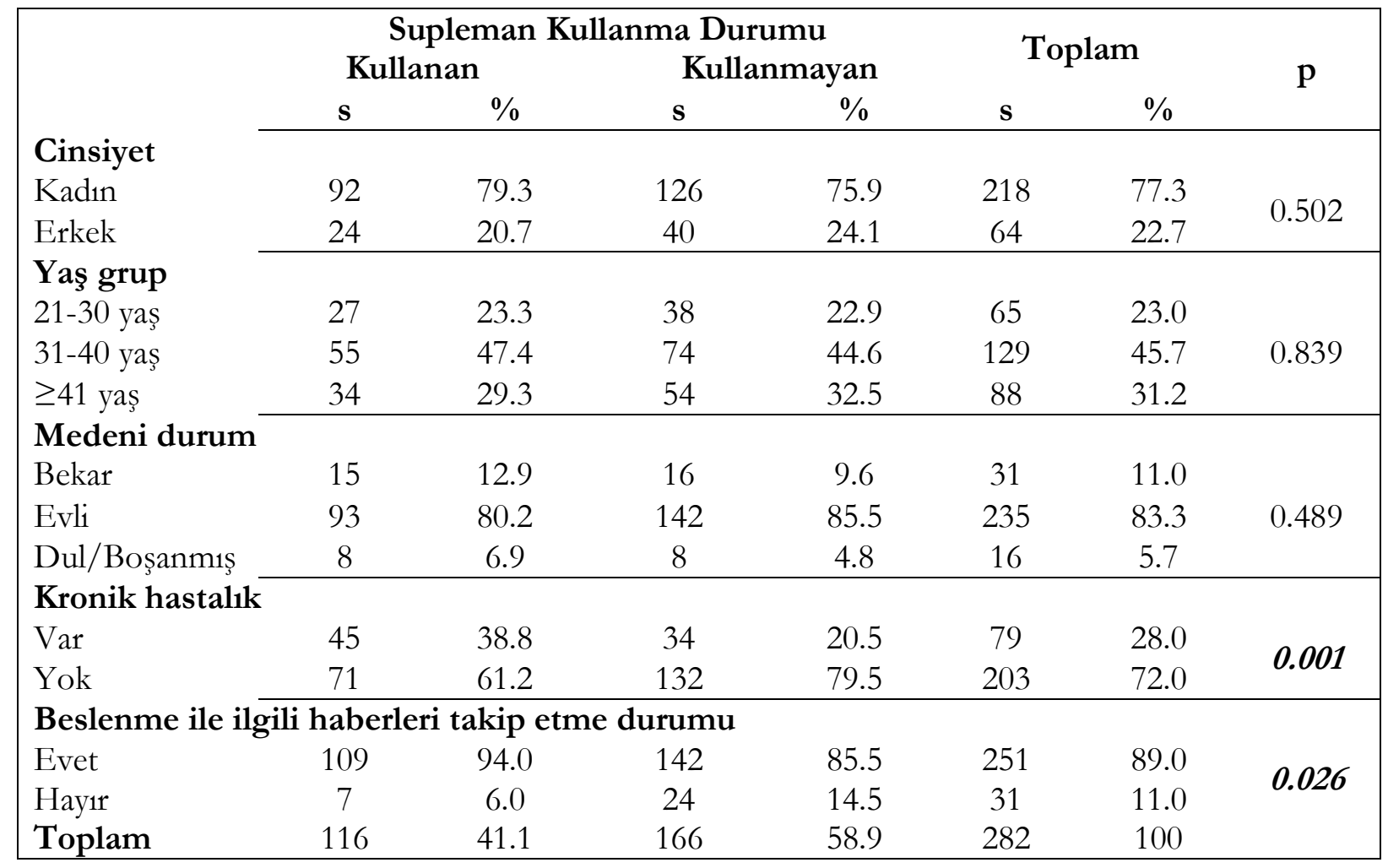

Diyet suplemanı kullanan öğretmenlerin \%79.3'ü kadın, \%20.7'si erkektir ( $\mathrm{p}>0.05$ ). Kadın öğretmenler en fazla multivitamin-mineral (\%41.3), demir (\%19.6), B grubu vitaminler (\%15.2) içeren vitamin-mineral desteklerini kullanırken; erkekler en fazla multivitamin-mineral (\%41.7), B grubu vitaminler (\%25.0)ve çinko (\%12.5) kullandığını belirtmiştir. Vitamin-mineral desteği kullananların \%24.2'si her gün, \%12.1'i haftada 2-3 kez, \%10.3'ü haftada 1 kez, \%53.4'ü daha seyrek kullandığını ifade etmiştir. Kullanma önerilerini ise \%76.7'si doktor, \%10.3'ü diğer sağlık personelinden aldıklarını ve \%12.9'u ise herhangi bir sağlık personeline danışmaksızın kullandığını belirtmiştir.

Öğretmenlerin vitamin-mineraller ile ilgili bilgi sorularından elde edilen ortalama puanları 13.7 \pm 2.18 , sağlık inanışları ile ilgili sorulardan elde edilen ortalama puanlar1 ise $31.4 \pm 5.72$ 'dir (Tablo 2).

Yaş arttıkça öğretmenlerin ortalama vitamin-minerallerle ilgili bilgi puanlarının arttı̆̆1 belirlenmiş ve bu artış istatistiksel olarak anlamlı bulunmuştur $(\mathrm{p}<0.05)$. Kadınların ve diyet suplemanı kullanan öğretmenlerin sağlık inanış puanlarının daha yüksek olduğu saptanmıştır $(\mathrm{p}<0.05)$. 
Yardımcı, H., Başpınar, B., \& Özfer Özçelik, A. (2018). Öğretmenlerin sağlık inanışlanı ve diyet suplemanı kullanma durumu. Journal of Human Sciences, 15(1), 331-339. doi:10.14687/jhs.v15i1.5191

Tablo 2. Öğretmenlerin bazı özellikleri ile diyet suplemanı bilgi puanı ve sağlık inanış puanı arasındaki ilişkisi

\begin{tabular}{|c|c|c|c|c|}
\hline & Bilgi puanı & & ğl1k inanış & \\
\hline & $\overline{\mathrm{x}} \pm \mathrm{SD}$ & $\mathrm{p}$ & $\overline{\mathbf{x}} \pm \mathrm{SD}$ & $\mathrm{p}$ \\
\hline Cinsiyet* & & & & \\
\hline Kadın & $13.8 \pm 2.03$ & 0312 & $31.9 \pm 5.01$ & \\
\hline Erkek & $13.3 \pm 2.59$ & 0.312 & $29.2 \pm 7.17$ & 0.018 \\
\hline Yaş grubu** & & & & \\
\hline $21-30$ yaş & $12.8 \pm 2.16^{\mathrm{a}}$ & & $31.1 \pm 5.14$ & \\
\hline $31-40$ yaş & $13.7 \pm 2.10^{\mathrm{b}}$ & 0.001 & $31.2 \pm 5.90$ & 0.708 \\
\hline$\geq 41$ yaş & $14.1 \pm 2.17^{\mathrm{ab}}$ & & $31.7 \pm 5.76$ & \\
\hline Supleman* & & & & \\
\hline Kullanıyor & $13.9 \pm 2.33$ & $0 \cap 74$ & $32.9 \pm 4.57$ & $a$ ano \\
\hline Kullanmiyor & $13.5 \pm 2.06$ & 0.014 & $30.3 \pm 6.12$ & 0.000 \\
\hline Kronik hastalık* & & & & \\
\hline Var & $13.9 \pm 2.18$ & & $32.1 \pm 5.98$ & \\
\hline Yok & $13.6 \pm 2.18$ & 0.437 & $31.1 \pm 5.54$ & 0.162 \\
\hline Genel toplam & 13. & & & \\
\hline
\end{tabular}

\section{TARTIŞMA SONUÇ ve ÖNERİLER}

Besin destekleri çok çeşitli olup, günlük diyetle alınan besin ögelerine ek olarak kullanılmaktadır. Besin desteklerinin kullanımı ve bilgisi ile ilgili ülkemizde yapılan çok fazla çalışma bulunmamaktadır. Bu çalışmada öğretmenlerin diyet suplemanı kullanma durumları, diyet suplemanı kullanma bilgileri ve sağlık inanışlarını saptamak amaçlanmıştır.

Besin desteklerinin performansı artırıc1, sağlığı geliştirici, beslenme yetersizliklerini önleyici, bağışılılı̆ı artırıcı, stresi azaltıcı gibi etkileri vardır. Besin suplemanları her gün milyonlarca insan tarafindan kullanılmaktadır. NHANES-III çalışmasında en az bir diyet suplemanı kullanma oranı \%53.0'tür (Gahche ve ark., 2011). Besin desteklerinin yaygin bir şekilde kullanıliyor olmasında bu yararlı etkilerinin yanında ulaşılabilirliğin kolay olması da etkilidir (Alhomoud ve ark., 2016). Bu çalışmada öğretmenlerin supleman kullanım sıklığı \%41.1 olarak saptanmıştır. Besin desteklerinin kullanılmasında bireysel farklılıkların göz önünde bulundurulması önemlidir. Özellikle mesleki anlamda öğretmenlerin yoğun çalışma saatlerinin olması bu meslek grubunda daha fazla diyet suplemanına ihtiyacın olabileceğini düşündürmektedir. Elde edilen bu sonuç genel olarak besin destekleri kullanımının, diğer ülkelerde olduğu gibi Türkiye'de de benzer şekilde artma eğiliminde olduğunu göstermektedir.

Supleman kullanımının yaşa, eğitim durumuna bağlı olarak arttığı, kadınlarda daha yaygın olduğu bilinmektedir (Ishihara ve ark., 2003; Block ve ark., 2007). Ayranc1 ve ark. (2005) yaptıklar1 bir çalışmada supleman kullanımının yaş, cinsiyet, fiziksel aktivite ve sigara içme durumuyla ilişkili olduğunu saptamışlardır $(\mathrm{p}<0.05)$. Bu çalışmada da kadınların $(\% 42.2)$ erkeklere $(\% 37.5)$ göre daha yüksek oranda besin destekleri kullandıkları belirlenmiştir ( $\mathrm{p}>0.05)$. Vatanparast ve ark.'ları (2010), diyet suplemanı kullanımının, yaş ve cinsiyetin yanı sıra hastalık durumu ve sosyoekonomik düzeyden de etkilenebileceğini belirtmişlerdir. Diyet suplemanı uygulamaları bireye özgü olmalı ve genellikle beslenme ile ilintili sağlık sorunları olduğunda ve sağlık profesyonellerinin önerdiği doz ve sürede kullanılmalıdır. Ancak bu çalışmada kronik hastalığı olmayanların diyet suplemanı kullanım sıklığının daha yüksek olduğu belirlenmiştir $(\mathrm{p}<0.05)$ (Tablo 1). Bununla birlikte beslenme ile ilgili 
Yardımcı, H., Bașpınar, B., \& Özfer Özçelik, A. (2018). Öğretmenlerin sağlık inanışlanı ve diyet suplemanı kullanma durumu. Journal of Human Sciences, 15(1), 331-339. doi:10.14687/jhs.v15i1.5191

haberleri takip edenlerde diyet suplemanlarının kullanım sıklığı (\%94.0) anlamlı olarak daha yüksektir (p<0.05). Örneğin Steele \& Senekal, (2005), reklamların supleman kullanımını etkileyen önemli faktörler arasında olduğunu ifade etmektedirler. Diyet suplemanlarının yaygın kullanımıyla artan popülaritesinin bu durumu etkilediği düşünülmektedir.

NHANES-III verilerine göre yetişkinler arasında en sık kullanılan diyet suplemanı (yaklaşık \%40) multivitamin-minerallerdir. Bunu yalnızca vitaminler ve yalnızca mineraller takip etmektedir. En sik kullanilan vitamin destekleri $\mathrm{C}$ ve $\mathrm{E}$, mineral destekleri ise kalsiyum ve demirdir (Gahche ve ark., 2011). Sharma \& Adiga'nın (2014) yaptıkları bir çalışmada en sık kullanılan besin desteklerinin multivitaminler, C vitamini ve B grubu vitaminlerinin olduğu belirlenmiştir. Bu çalışmada da literatürle uyumlu olarak en sik kullanilan diyet suplemanı multivitamin-mineral suplemanları $(\% 20.7)$ olmuştur. Bunu demir (\%15.2) ve B grubu vitaminleri (\%8.1) takip etmektedir. Bunun nedeninin öğretmenlerin yoğun iş temposu gereği daha dinç olmak istemeleri, hala ülkemizde özellikle kadınlarda daha sık görülen anemi belirtilerin önlenmesine yönelik olabileceği düşünülmektedir. Daha önce yapılan çalışmalarda sıklıkla sağlığın korunması ve yeterli ve dengeli beslenmenin sağlanması için supleman kullanıldığı saptanmıştır (Al Naggar \& Chen, 2011; Sharma ve ark., 2014; Lieberman ve ark., 2015).

Sharma ve ark.'nın (2014) yaptıkları çalısmada, diyet suplemanlarının büyük çoğunluğunun doktora danışılarak, ailenin yönlendirmesiyle ve internet aracılı̆̆ıla bilgi alınarak kullanıldığ1 belirlenmiştir. Yapılan başka bir çalışmada da benzer şekilde aile ve internetten bilgi alınarak diyet suplemanı kullanıldığı saptanmıştır (Lieberman ve ark., 2015). Türkiye'de yapılan bir çalışmada ise bireylerin yalnızca \%11'inin herhangi bir sağlık personeline danışarak, büyük çoğunluğunun ise ülkemizde sıklıkla kullanılan kitle iletişim aracı olan televizyonun etkisi ile diyet suplemanı kullandığ1 saptanmıştır (Ayranc1 ve ark., 2005). Bu çalışmada öğretmenlerin büyük çoğunluğu (\%87.0), sağlık personeline danışarak diyet suplemanı kullandığını belirtmiştir. Bunun nedeninin sağlıkla ilgili konularda karar vermede eğitim düzeyi ve farkındalığın daha fazla olmasından kaynaklandığı düşünülmektedir. Beslenme bilgilerinin doğru ve güvenilir kaynaklardan elde edilmesi meydana gelebilecek sağlık sorunlarının önlenmesinde etkilidir (Ayrancı ve ark., 2005). Bilinçsiz kullanımın yol açacağı problemler hesaba katıldığında supleman kullanımında bilgi alınan yerin önemi daha da artmaktadir.

Sağlık inanışları beslenme alışkanlıklarını etkileyebilmektedir (Hayes \& Ross, 1987). Yapılan bir çalışmada sağlık inanış puanının, kadınlarda daha yüksek olduğu belirlenmiştir (Wardle ve ark., 2004). Bu çalışmada öğretmenlerin sağlık inanış puanlarının yaşla birlikte arttı̆̆1, kronik hastalı̆̆1 olanlarda, kadınlarda ve supleman kullananlarda anlamlı olarak daha yüksek olduğu belirlenmiştir $(p<0.05)$ (Tablo 2). Bunun nedeni sağılk hakkında bilgi sahibi olan bireylerin diyet suplemanlarının sağllğa yararlı etkilerinden yararlanmak istemeleri olabilir. Ancak Pelletier \& Kendall (1997), bunun aksine sağlıksız beslenme tutum ve davranışı olan bireylerin diyet örüntülerini dengeleyebilmek için diyet suplemanı kullanma eğilimleri olduğunu savunmuştur. Aina \& Ojedokun (2014) yaptıkları çalışmada ise, bilinçsiz supleman kullanımının yol açabileceği sağlık problemleri hakkında yeterli bilgiye sahip olunmadığını belirlemiştir.

Alhomoud ve ark.'nın (2016) yaptıkları çalısmada suplemanlarla ilgili bilgi puanı yüksek olan bireylerin, diyet suplemanı kullanma sıklığının daha yüksek olduğunu, benzer şekilde Valentine (2015) bireylerin bilgi düzeyi artması ile diyet suplemanı kullanım sıklığının arttı̆̆ını saptamışlardır. Diyet suplemanları kullanım sıklı̆ının artmasındaki nedenler arasında, konu hakkında daha fazla bilgi sahibi olunmasına bağlı sağlıkla ilgili olumlu değişimlerin olabileceği olabilir. Bu çalışmada da benzer şekilde bilgi puanı yüksek olan öğretmenlerin supleman kullanma sıklı̆̆ daha yüksek bulunmuştur ancak bu durum istatistiksel olarak anlamlı değildir. Buna ek olarak öğretmenlerin diyet suplemanı bilgilerinin kadınlarda ve kronik hastalı̆̆ı olanlarda daha yüksek olduğu ve yaş arttıkça bilgi puanının anlamlı olarak arttığı belirlenmiştir $(\mathrm{p}<0.05)$ (Tablo 2). 
Yardımcı, H., Bașpınar, B., \& Özfer Özçelik, A. (2018). Öğretmenlerin sağlık inanışlanı ve diyet suplemanı kullanma durumu. Journal of Human Sciences, 15(1), 331-339. doi:10.14687/jhs.v15i1.5191

Yeterli ve dengeli beslenme, sağlı̆̆ın korunmasında ve geliştirilmesinde etkilidir. Besin ögesi yetersizliklerinde ve hastalıklardan korunmada diyet suplemanı kullanımının önemli rol oynadığ1 bilinmektedir. Ancak bilinçsiz kullanımın ve olası yan etkilerin oluşmasının önlenmesinde bilginin kaynağının doğruluğundan emin olunmalıdır. Öğretmenler arasında diyet supleman kullanım sıklığı yüksek olmasına rağmen sağlık inanışları ile diyet suplemanı kullanımı hakkındaki bilgileri yeterli değildir. Öğretmenlerin gelecek nesiller üzerinde sağlıklı yeme davranışları olușturma potansiyelleri göz önünde bulundurulduğunda beslenme ve popülerliği artan diyet suplemanı kullanımı hakkında yeterli ve doğru bilgi alabilmeleri için eğitimler verilmelidir.

Diyet suplemanlarının kullanımında değişik tüketici gruplarının olması nedeni ile bu grupların duyarlılı̆̆ının bilinmesi önemlidir. Yeterli ve dengeli beslenme sağlı̆̆ın temel bileşenlerindendir. Günlük beslenme düzeni içinde besinlerle alınan besin ögesi miktarları göz önünde bulundurularak, eklenebilecek besin destekleri miktarının ne miktarda olabileceğinin hesaplanmasının uygun olacağı düşünülmektedir.

\section{KAYNAKÇA}

Aina, B. A., \& Ojedokun, O. A. (2014). Knowledge anduse of dietary supplements by students of College of Medicine, University of Lagos, Idi-Araba, Lagos, Nigeria. Journal of Basic And Clinical Pharmacy, 5(2), 34.

Alhomoud, F. K., Basil, M., \&Bondarev, A. (2016). Knowledge, attitudes and aractices (KAP) relating to dietary supplements among health sciences and non-health sciences students in one of The Universities of United Arab Emirates (UAE). Journal of Clinical and Diagnostic Research: JCDR, 10(9), JC05.

Al-Naggar, R. A.,\& Chen, R. (2011). Prevalence of vitamin-mineral supplements use and associated factors among young Malaysians. Asian Pacific Journal of Cancer Prevention, 12(4), 1023-1029.

Ayranci, U., Son, N., \& Son, O. (2005). Prevalence of nonvitamin, nonmineral supplement usage among students in a Turkish university. BMC Public Health, 5(1), 47.

Block, G.,Jensen, C. D., Norkus, E. P., Dalvi, T. B., Wong, L. G., McManus, J. F., \& Hudes, M. L. (2007). Usage patterns, health, and nutritional status of long-term multiple dietary supplement users: a crosssectional study. Nutrition Journal, 6, 30. Retrieved from: https:/ /doi.org/10.1186/1475-2891-6-30

Conner, M., Kirk, S. F., Cade, J. E., \& Barrett, J. H. (2001). Why do women use dietary supplements? The use of the theory of planned behaviour to explore beliefs about their use. Social Science \& Medicine, 52(4), 621-633.

Eldridge, A. L., \& Sheehan, E. T. (1994). Food supplement use and related beliefs: survey of community college students. Journal of Nutrition Education, 26(6), 259-265.

Fontanarosa, P. B., Rennie, D., \& DeAngelis, C. D. (2003). The need for regulation of dietary supplements-lessons from ephedra. JAMA, 289(12), 1568-1570.

Frankos, V. H., Street, D. A., \& O'neill, R. K. (2010). FDA regulation of dietary supplements and requirements regarding adverse event reporting. Clinical Pharmacology \& Therapeutics, 87(2), 239 244.

Gahche, J., Bailey, R., Burt, V., Hughes, J., Yetley, E., Dwyer, J., ...\& Sempos, C. (2011). Dietary supplement use among US adults has increased since NHANES III (1988-1994). NCHS data brief, 61, 1-8.

Hayes, D., \& Ross, C. E. (1987). Concern with appearance, health beliefs, and eating habits. Journal of Health and Social Behavior, 120-130.

Ishihara, J., Sobue, T., Yamamoto, S., Sasaki, S., Tsugane, S. (2003). Demographics, lifestyles, health characteristics, and dietary intake among dietary supplement user in Japan. Int J Epidemiol; 32(4), 546553.

Lieberman, H. R.,Marriott, B. P., Williams, C., Judelson, D. A., Glickman, E. L., Geiselman, P. J., ... \& Mahoney, C. R. (2015). Patterns of dietary supplement use among college students. Clinical Nutrition, 34(5), 976-985.

Olstad, D. L., Raine, K. D., \& Nykiforuk, C. I. (2014). Development of a report card on healthy food environments and nutrition for children in Canada. Preventive medicine, 69, 287-295.

Pelletier, D. L., \& Kendall, A. (1997). Supplement use may not be associated with better food intake in all population groups. Family Economics and Nutrition Review, 10(4), 32. 
Yardımcı, H., Bașpınar, B., \& Özfer Özçelik, A. (2018). Öğretmenlerin sağlık inanıșlanı ve diyet suplemanı kullanma durumu. Journal of Human Sciences, 15(1), 331-339. doi:10.14687/jhs.v15i1.5191

Rossiter, M.,Glanville, T., Taylor, J., \& Blum, I. (2007). School food practices of prospective teachers. Journal of School Health, 77(10), 694-700.

Sharma, A., \& Adiga, S. (2014). Knowledge, attitude and practices related to dietary supplements and micronutrients in health sciences students. Joumal of Clinical and Diagnostic Research: JCDR, 8(8), HC10.

Steele, M., \& Senekal, M. (2005). Dietary supplement use and associated factors among university students. South African Journal of Clinical Nutrition, 18(1), 17-30.

Valentine, A. A. (2015). Dietary Supplement Use, Perceptions, and associated lifestyle behaviors in undergraduate college students, student-athletes, and ROTC cadets. Retrieved from: http://search.proquest.com/docview/1694582844?accountid=12874.

Vatanparast, H.,Adolphe, J. L., \& Whiting, S. J. (2010). Socio-economic status and vitamin/mineral supplement use in Canada. Health Reports, 21(4), 19-25.

Waddington, F., Naunton, M., Kyle, G., Thomas, J., Cooper, G., \& Waddington, A. (2015). A systematic review of community pharmacist therapeutic knowledge of dietary supplements. International Journal of Clinical Pharmacy, 37(3), 439-446.

Wardle, J.,Haase, A. M., Steptoe, A., Nillapun, M., Jonwutiwes, K., \& Bellisie, F. (2004). Gender differences in food choice: the contribution of health beliefs and dieting. Annals of Behavioral Medicine, 27(2), 107116.

World Health Organization. (2007). Preventing and controlling micronutrient deficiencies in populations affected by an emergency. Joint Statement by the World Health Organization, the World Food Programme and the United Nations Children's Fund. Retrieved from: http://www.who. int/nutrition/publications/nut_emergencies/en/index. Html.

Yeh, M. C. P. (2000). Nutrition knowledge, health beliefs and use of nutrition supplements among older adults in Northwestern Wisconsin (Doctoral dissertation, University of Wisconsin-Stout), 90p.

\section{Introduction}

\section{Extended English Summary}

Nutrition plays a key role in maintaining healthy life and protecting from diseases (Alhomoud et al., 2016). Vitamin mineral deficiencies, which can be seen due to inadequate and unbalanced nutrition, are an important risk factor for fatal and chronic diseases (WHO, 2007). Vitamins and minerals play a key role in many physiological events such as cell defense, antioxidant mechanisms and prevention of chronic diseases (Al-Naggar \& Chen, 2011; Block et al., 2007). However about 2 million people are known to have vitamin-mineral deficiency (Micronutrient, 2009). In this context, the use of dietary supplements is descriptive and therapeutic. The use of dietary supplement is rapidly increasing worldwide (Waddington et al., 2015). However, it should be taken into account that the lack of adequate knowledge and control of the supplements will threaten the safety of the public (Fontanarosa et al., 2003). Nutritional knowledge is decisive in rational use of dietary supplements and in making appropriate choices (Sharma \& Adiga, 2014). There have been few studies in the literature to examine the relationship between the use of dietary supplements, knowledge about dietary supplements and health beliefs that significantly influence nutritional behavior.

This study was conducted to determine the knowledge about dietary supplements, health beliefs and the use of dietary supplements by teachers who play an important role in providing healthy eating habits of children throughout life.

\section{Method}

The sampling of the study consisted of 282 volunteering teachers working in elementary schools in Ankara province. The questionnaire form consisted of four parts: general information, use of vitamin-minerals, questions about vitamin-minerals (20 questions), and health beliefs. To calculate the knowledge scores, correct responses were assigned " 1 " and incorrect responses " 0 " (min 0, max 20 points). A 5-point Likert-type scale was used to determine the beliefs and calculate the related scores (Min 0, max 45 points). The study findings were analyzed with SPSS software packet using suitable statistical methods. 
Yardımcı, H., Bașpınar, B., \& Özfer Özçelik, A. (2018). Öğretmenlerin sağlık inanıșlanı ve diyet suplemanı kullanma durumu. Journal of Human Sciences, 15(1), 331-339. doi:10.14687/jhs.v15i1.5191

\section{Results, Conclusion, and Recommendations}

The sampling of the study involved a total of 282 volunteering teacher, 64 males $(22.7 \%)$ and 212 females $(77.3 \%)$. Forty one point five percent of the teachers stated that they used supplemental vitamins and minerals, and $38.5 \%$ of the vitamin-mineral users said that they had chronic diseases. The most common chronic diseases in women were iron deficiency diseases (32.6\%), iodine deficiency diseases (11.9\%), osteoporosis and hypertension (4.1\%); In men are hypertension $(50 \%)$, diabetes $(25 \%)$, osteoporosis $(12.5 \%)$.It was determined that the most commonly used food supplements were vitamin-mineral supplements. Seventy six point one percent of those taking nutritional supplements stated they used this support with doctor recommendation. It was found that the average vitamin-mineral related knowledge score of the participants was $14.3 \pm 2.6$ ( $\min 7$, max 20 points), and that the mean knowledge score of women (14.5 \pm 2.6$)$ was significantly higher than the average knowledge score of men $(13.7 \pm 2.5)(p<0.05)$. When considered according to age groups, it was determined that the average knowledge score of the participants aged 41 and over was the highest $(14.8 \pm 2.5)$, the mean knowledge score of 21 30 age group was the lowest (13.2 \pm 3.0$)$, and that this difference was statistically significant $(p<0.05)$. The mean belief score of the teachers was found to be $29.2 \pm 2.8$, and it was determined that the mean belief score was statistically significant with respect to gender and age groups $(\mathrm{p}<0.05)$.

There is not much work done in our country regarding the use and knowledge of dietary supplements. According to NHANES-III study, the rate of using at least one dietary supplement was 53.0\% (Gahche et al., 2011). Dietary supplements are widely used because they are easily accessible and have beneficial effects on health (Alhomoud et al., 2016). In this study, the frequency of use of diet supplements by teachers was $41.1 \%$.

It is known that the use of dietary supplements increases with age and education, and is more common in female (Block et al., 2007). In the study performed by Ayranc1 et al. (2005), the use of dietary supplements was found to be related to age, gender, physical activity and smoking status $(\mathrm{p}<0.05)$. In this study, it was determined that female $(42.2 \%)$ used dietary supplements higher than males $(37.5 \%)$ ( $>>0.05)$. Vatanparast et al. (2010) stated that the use of dietary supplements may be affected by age and gender, as well as chronic disease status and socioeconomic status. In this study, it was determined that the frequency of use of dietary supplements was higher in teacher without chronic disease $(\mathrm{p}<0.05)$.

Health beliefs are known to affect nutritional habits (Hayes and Ross, 1987). In a study conducted, it was determined that the health belief score was higher in women (Wardle et al., 2004).

In this study, it was determined that the teachers' health belief scores increased with age and were higher in teachers with chronic disease. Also the score was significantly higher in women and teachers using dietary supplement $(\mathrm{p}<0.05)$. This may be due to the fact that individuals who are knowledgeable about health may want to benefit from the beneficial effects of diet supplements on health. However, Pelletier \& Kendall (1997), on the contrary, argued that individuals with unhealthy nutritional attitudes and behaviors tend to use diet supplements to regulate dietary patterns. In parallel with this study, Alhomoud et al. (2016) was found that the frequency of using dietary supplements is higher for teachers whose higher knowledge score about nutrition.

Despite the high frequency of dietary supplement use among teachers, health belief scores and knowledge about dietary supplement are not sufficient. It was found that supplement use of teachers was associated with health beliefs, chronic illness, and following the nutrition related magazine. There are some important points still unknown and to need attention in the use of food supplement that has become increasingly common in recent years. 